\title{
Xylitol production from xylose mother liquor: a novel strategy that combines the use of recombinant Bacillus subtilis and Candida maltosa
}

\author{
Hairong Cheng ${ }^{1}$, Ben Wang ${ }^{1,2}$, Jiyang LV1', Mingguo Jiang ${ }^{2 *}$, Shuangjun Lin ${ }^{1}$, Zixin Deng ${ }^{1 *}$
}

\begin{abstract}
Background: Xylose mother liquor has high concentrations of xylose (35\%-40\%) as well as other sugars such as Larabinose $(10 \%-15 \%)$, galactose (8\%-10\%), glucose (8\%-10\%), and other minor sugars. Due to the complexity of this mother liquor, further isolation of xylose by simple method is not possible. In China, more than 50,000 metric tons of xylose mother liquor was produced in 2009, and the management of sugars like xylose that present in the lowcost liquor is a problem.

Results: We designed a novel strategy in which Bacillus subtilis and Candida maltosa were combined and used to convert xylose in this mother liquor to xylitol, a product of higher value. First, the xylose mother liquor was detoxified with the yeast C. maltosa to remove furfural and 5-hydromethylfurfural (HMF), which are inhibitors of $B$. subtilis growth. The glucose present in the mother liquor was also depleted by this yeast, which was an added advantage because glucose causes carbon catabolite repression in B. subtilis. This detoxification treatment resulted in an inhibitor-free mother liquor, and the C. maltosa cells could be reused as biocatalysts at a later stage to reduce xylose to xylitol. In the second step, a recombinant $B$. subtilis strain with a disrupted xylose isomerase gene was constructed. The detoxified xylose mother liquor was used as the medium for recombinant B. subtilis cultivation, and this led to L-arabinose depletion and xylose enrichment of the medium. In the third step, the xylose was further reduced to xylitol by C. maltosa cells, and crystallized xylitol was obtained from this yeast transformation medium. C. maltosa transformation of the xylose-enriched medium resulted in xylitol with $4.25 \mathrm{~g} \mathrm{~L}^{-1} \cdot \mathrm{h}^{-1}$ volumetric productivity and $0.85 \mathrm{~g}$ xylitol/g xylose specific productivity.

Conclusion: In this study, we developed a biological method for the purification of xylose from xylose mother liquor and subsequent preparation of xylitol by C. maltosa-mediated biohydrogenation of xylose.
\end{abstract}

\section{Background}

Xylose is used to prepare xylitol by chemical hydrogenation and is purified from the acid hydrolysate of sugarcane bagasse or corncob, which are widely available in China or other countries. The acid hydrolysate of sugarcane bagasse or corncob contains xylose, L-arabinose, glucose, galactose, mannose, and other minor monosaccharides $[1,2]$. It also contains two major inhibitors, i.e.,

\footnotetext{
* Correspondence: mzxyjiang@163.com; zxdeng@sjtu.edu.cn

'Laboratory of Microbial Metabolism and School of Life Sciences and Biotechnology, Shanghai Jiao Tong University, 800\# Dongchuan Road, Shanghai, China

${ }^{2}$ Key Laboratory of Chemical and Biological Transforming Process, School of Chemistry and Ecology Engineering, Guangxi University for Nationalities, Nanning, China

Full list of author information is available at the end of the article
}

furfural and 5-hydroxymethylfurfural (HMF), which are the degradation products of xylose and glucose, respectively [3]. These two major inhibitors have deleterious effects on the growth of microorganisms $[4,5]$. The acid hydrolysate is first purified on an ion-exchange resin to decrease its conductivity to less than $20 \mu \mathrm{S} / \mathrm{cm}$ and is then concentrated. Xylose is crystallized and separated from the concentrated acid hydrolysate by three or more rounds of gradient cooling. This produces a hydrolysate, known as the xylose mother liquor, which is abundant, low in cost, and can be used as a feedstock. It is a viscous and reddish-brown liquor that contains $35 \%-40 \%$ xylose, $10 \%-15 \%$ L-arabinose, $8 \%-10 \%$ glucose, and $8 \%-10 \%$ D-galactose.

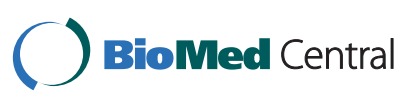

() 2011 Cheng et al; licensee BioMed Central Ltd. This is an Open Access article distributed under the terms of the Creative Commons Attribution License (http://creativecommons.org/licenses/by/2.0), which permits unrestricted use, distribution, and reproduction in any medium, provided the original work is properly cited. 
In China, more than 50,000 metric tons of xylose mother liquor was produced in 2009, and the management of sugars like xylose that present in the low-cost liquor is a problem. Attempts have been made to improve the value of the xylose mother liquor by individually separating xylose, L-arabinose, and galactose by simulated moving bed chromatography. However, this method is difficult to adopt due to its high running costs and equipment investments as well as its unsatisfactory and low separation efficiency. In recent times, biological removal and biotransformation have become more attractive approaches for producing high-value compounds from crude sugar feedstocks [6]. Bacillus subtilis is a generally regarded as safe bacterium and is used in probiotics [7]. This bacterium can grow well in medium containing xylose, L-arabinose, glucose, and galactose, and it can utilize these sugars as carbon sources. At least three genes are involved in xylose metabolism- $x y l A, x y l B$, and $x y l R$. Together, these three genes constitute the xylose utilization operon. Xylose utilization by $B$. subtilis requires the production of $x y l A$ and $x y l B$, which is regulated at the transcriptional level by a xylose-responsive repressor protein encoded by $x y l R$ and by carbon catabolite repression [8]. B. subtilis cannot utilize xylose when the xylose isomerase gene is disrupted by insertional inactivation, but it can still metabolize L-arabinose, galactose, and glucose. Thus, xylose is enriched in the xylose mother liquor by the selective utilization of other sugars. If yeasts are then cultured in this mother liquor, they can efficiently synthesize xylitol from it. However, B. subtilis cannot survive in a medium containing more than $10 \%$ xylose mother liquor due to the latter's furfural and HMF content, which can severely inhibit the growth of microorganisms by reducing cellular enzymatic biological activities, causing DNA degradation and membrane damage [5,9-11]. Candida maltosa ATCC28140 is capable of detoxifying furfural and HMF, and this organism grows well in a medium containing 35\% xylose mother liquor. Also, this yeast can hydrogenate sugars to their corresponding sugar alcohols, for example, it can efficiently convert xylose to xylitol [12].

In this study, we designed a three-step process to biologically produce xylitol from xylose mother liquor. First, the xylose mother liquor was treated with C. maltosa to remove the inhibitory compounds furfural and HMF as well as glucose. The yeast cells and detoxified xylose mother liquor were recovered by centrifugation. We then constructed a genetically modified $B$. subtilis in which the xylose isomerase gene was disrupted. B. subtilis with the disrupted xylose isomerase gene was then cultured in the detoxified xylose mother liquor to enrich xylose; this enrichment results from the biological removal of other sugars such as L-arabinose and some of the galactose. The resulting xylose-enriched mother liquor was treated with C. maltosa cells to allow conversion of xylose to xylitol. After further purification by activated carbon and ion-exchange treatment, crystallized xylitol was obtained from the above-described yeast transformation medium.

\section{Methods}

\section{Microorganisms and media}

The strains and plasmids used in this study are listed in Table 1. Luria-Bertani (LB) agar was used to cultivate the $B$. subtilis strains, and the medium was supplemented with chloramphenicol $\left(25 \mathrm{mg} \mathrm{L}^{-1}\right)$ when necessary. The SP salt solution contained $0.2 \%\left(\mathrm{NH}_{4}\right)_{2} \mathrm{SO}_{4}, 1.4 \% \mathrm{~K}_{2} \mathrm{HPO}_{4}, 0.6 \%$ $\mathrm{KH}_{2} \mathrm{PO}_{4}, 0.02 \% \mathrm{MgSO}_{4} \cdot 7 \mathrm{H}_{2} \mathrm{O}$, and $0.1 \%$ sodium citrate. The CAYE solution $(100 \times)$ consisted of $2 \%$ casamino acids and $10 \%$ bacto-yeast extract. The SPI medium (SP salt solution supplemented with $0.5 \%$ sugar and $1 \% 100 \times$ CAYE) and SPII medium (SPI medium supplemented with $1 \% 50 \mathrm{mM} \mathrm{CaCl}_{2}$ and $1 \% 250 \mathrm{mM} \mathrm{MgCl}_{2}$ ) were used for B. subtilis transformation. The xylose mother liquor used in this study was purchased from Jiahe Sugar Co. Ltd.(Changyi City, Shandong Province, China), it contains $690 \mathrm{~g} \mathrm{~L}^{-1}$ dissolved solids (DS) consisting of $350 \mathrm{~g} \mathrm{~L}^{-1}$ xylose, $150 \mathrm{~g} \mathrm{~L}^{-1} \mathrm{~L}$-arabinose, $80 \mathrm{~g} \mathrm{~L}^{-1}$ glucose, $80 \mathrm{~g} \mathrm{~L}^{-1}$ galactose, and less than $30 \mathrm{~g} \mathrm{~L}^{-1}$ unknown sugars (mannose, rhamnose, and oligosaccharides).

\section{Plasmid construction}

The xylA gene was amplified by PCR using PxylA-F and PxylA-R as gene-specific primers and genomic DNA from B. subtilis subsp. subtilis 168 as the template. The PCR fragment ( $x y l A$ gene) was ligated to the pMD18 Tsimple vector to form the recombinant plasmid pMDxylA. The latter was digested with $K p n \mathrm{I}$ and $S a c \mathrm{I}$, and the fragment $K p n \mathrm{I} / x y l A / S a c \mathrm{I}$ was released. This fragment was ligated with KpnI- and SacI-digested pBlueScript II SK(-), resulting in the recombinant plasmid pBS-xylA. The $\mathrm{cm}^{\mathrm{r}}$ gene was amplified by PCR using Pcm-F and Pcm-R as gene-specific primers and plasmid pBCJ164.3 as the template. The DNA fragment

Table 1 Bacterial strains, yeast strain, and plasmids used in this study

\begin{tabular}{lll}
\hline Strain or plasmid & Relevant marker(s) & Source \\
\hline Bacillus subtilis subsp. subtilis 168 & $\operatorname{trpC2}$ & BGSC 1A1 \\
Candida maltosa ATCC28140 & & ATCC \\
pBlueScript II SK(-) & $A p^{r}$ & Stratagene \\
pBCJ164.3 & $A p^{r} \mathrm{Cm}^{r}$ & BGSC ECE176 \\
pMD-xyl & $A p^{r}$ & This study \\
pMD-cm & $A p^{r} \mathrm{Cm}^{r}$ & This study \\
pBS-Xyl & $A p^{r}$ & This study \\
pBS-Xyl-Cm & $A p^{r} \mathrm{Cm}^{r}$ & This study \\
\hline
\end{tabular}


$(0.65 \mathrm{~kb})$ was ligated to the $\mathrm{pMD} 18 \mathrm{~T}$-simple vector to form $\mathrm{pMD}-\mathrm{cm}$. The recombinant plasmid $\mathrm{pMD}-\mathrm{cm}$ was then digested with $N d e I$. The $N d e I / c m / N d e I$ fragment that was released was ligated with NdeI-digested pBSxylA, resulting in the recombinant plasmid pBS100 (Figure 1). The $x y l A$ gene was disrupted by insertion of the chloramphenicol resistance gene $(\mathrm{cm})$. All the primers used here are listed in Table 2.

\section{Bacterial transformation}

The B. subtilis subsp. subtilis 168 strain to be transformed was streaked on an LB agar plate and incubated at $37^{\circ} \mathrm{C}$. A single colony was inoculated in $3 \mathrm{~mL} \mathrm{LB}$ broth and cultured overnight. A $200-\mu \mathrm{L}$ aliquot of the culture was transferred to $8 \mathrm{~mL}$ SPI medium and cultured at $37^{\circ} \mathrm{C}$ and $200 \mathrm{rpm}$ until its $\mathrm{OD}_{600}$ reached approximately $0.8-1.2$. Next, $200 \mu \mathrm{L}$ of this culture was transferred to $2 \mathrm{~mL}$ SPII medium and cultured at $100 \mathrm{rpm}$ for $90 \mathrm{~min}$. EGTA $\left(20 \mu \mathrm{L}\right.$ of a $10 \mathrm{mmol} \mathrm{L}^{-1}$ solution) was added to this culture, which was left to incubate for an additional $10 \mathrm{~min}$ at $100 \mathrm{rpm}$. The cells were divided into $500-\mu \mathrm{L}$ aliquots and placed in $1.5-\mathrm{mL}$ Eppendorf tubes. The $P v u \mathrm{II}$-linearized plasmid pBS100 $(5 \mu \mathrm{L})$ was added to $500 \mu \mathrm{l}$ of competent cells and incubated for $90 \mathrm{~min}$ at $100 \mathrm{rpm}$. All the cells were then plated onto two LB agar plates supplemented with chloramphenicol $\left(25 \mu \mathrm{g} \mathrm{mL}{ }^{-1}\right)$ and incubated at $37^{\circ} \mathrm{C}$ for 2 days until positive recombinants appeared.

Identification of the $x y \mid A$ gene-disrupted positive colonies Two transformants that grew on LB agar plates containing $25 \mu \mathrm{g} \mathrm{mL} \mathrm{m}^{-1}$ chloramphenicol were selected to check whether the xylose isomerase gene was disrupted by the insertion of the chloramphenicol resistance gene. Two sets of primers, i.e., PxylA-F and Pcm-R, Pcm-F and PxylA-R, were used to amplify the $1310 \mathrm{bp}$ and $1330 \mathrm{bp}$ fragments, respectively, from the genomic DNA of the two transformants. The genomic DNA of wild-type B. subtilis subsp. subtilis 168 was used as the negative

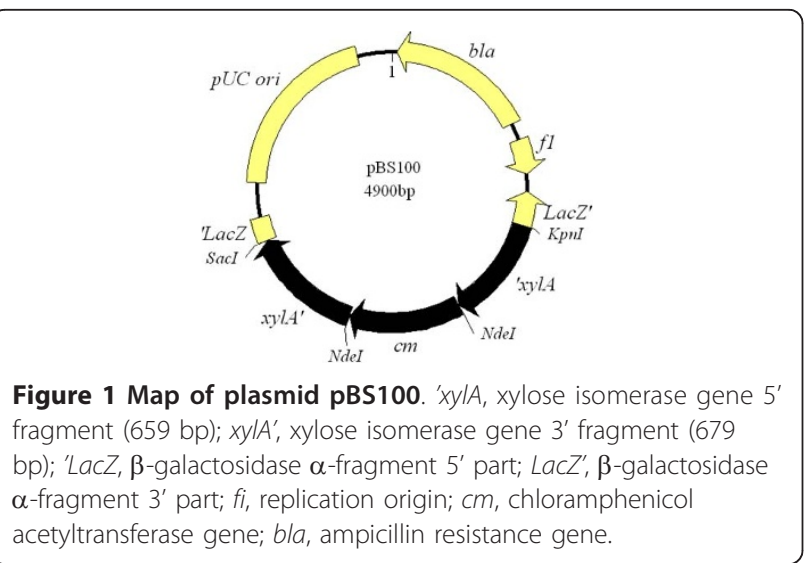

Table 2 Sequences of the primers used in this study

\begin{tabular}{lll}
\hline Primer & Sequence & $\begin{array}{l}\text { Enzyme } \\
\text { site }\end{array}$ \\
\hline PxylA-F & 5'-tg ggt acc atg gct caa tct cat tcc agt tc-3' & Kpnl \\
PxylA-R & 5'-tg gag ctc $t$ tat act tct aaa atg tat tgg ttc-3' & Sacl \\
Pcm-F & $5^{\prime}$-tg $\underline{\text { cat atg }}$ agg agg atg atg aac ttt aat aaa att & Ndel \\
& gat tta g-3' & \\
Pcm-R & 5'-tg cat atg tt ata aaa gcc agt cat tag gcc-3' & Ndel \\
\hline
\end{tabular}

Restriction sites are underlined.

control. To clarify recombinant cell extracts that had no xylose isomerase activity, recombinant (Bsxyl strain) and nonrecombinant cells were cultivated in $5 \mathrm{~mL}$ of liquid $\mathrm{LB}$ medium supplemented with $5 \mathrm{~g} \mathrm{~L}$-arabinose $\mathrm{L}^{-1}$ and $5 \mathrm{~g}$ xylose $\mathrm{L}^{-1}$ for $24 \mathrm{~h}$. They were then centrifuged at $10000 \mathrm{~g}$ and resuspended in $2 \mathrm{~mL}$ of $50 \mathrm{mM}$ Tris-Cl buffer ( $\mathrm{pH}$ 6.5). The cells were disrupted by supersonication, and clear supernatants were obtained by centrifugation. A $20-\mu \mathrm{L}$ aliquot of the supernatant was used as the crude enzyme and reacted with $200 \mu \mathrm{L}$ of $50 \mathrm{~g}$ $\mathrm{L}^{-1}$ xylose in $50 \mathrm{mM}$ Tris- $\mathrm{Cl}$ buffer $(\mathrm{pH} 6.5)$ at $37^{\circ} \mathrm{C}$ for $5 \mathrm{~h}$. Subsequently, $50 \mu \mathrm{L}$ of the reaction buffer was analyzed by HPLC to detect whether D-xylulose had formed from xylose.

To further clarify whether or not the recombinant cells could utilize xylose, recombinant and nonrecombinant $B$. subtilis subsp. subtilis 168 cells were cultivated in LB medium containing 1.0\% L-arabinose with or without chloramphenicol at $37^{\circ} \mathrm{C}$ and $200 \mathrm{rpm}$. The cells were collected by centrifugation and resuspended in LB broth containing $1.0 \%$ xylose, followed by culture at $37^{\circ} \mathrm{C}$ and $200 \mathrm{rpm}$. Samples were taken at regular intervals and subjected to high-performance TLC (using a silica gel plate purchased from Merck, Rahway, New Jersey) to determine the change in the xylose content. The silica plate was developed with a chromatography solution (pyridine:ethyl acetate:acetate:water $=5: 5: 3: 1$ ) in a developing tank. After completion, the plate was dried and sprayed with $1 \%$ sodium periodate. After further drying, it was sprayed with a color developing agent (1\% benzidine in $95 \%$ ethanol). The xylose spots were clearly visualized by this method.

\section{Removal of inhibitors by C. maltosa}

To evaluate the ability of $C$. maltosa to remove inhibitors, the cells were inoculated into synthetic dextrose medium containing $10 \mathrm{~g} \mathrm{~L}^{-1} \mathrm{YNB}$ (with histidine and ammonium sulfate, Difico ${ }^{\mathrm{TM}}$, MD, USA), $10 \mathrm{~g} \mathrm{~L}^{-1}$ glucose, and furfural ( $5 \mathrm{mM}, 10 \mathrm{mM}, 20 \mathrm{mM}, 30 \mathrm{mM}$, or $40 \mathrm{mM}$, TCI, Tokyo) or HMF (in the same range from $5 \mathrm{mM}$ to $40 \mathrm{mM}$, TCI, Tokyo). In the case of furfural, 1 $\mathrm{mL}$ furfural was first resolved in $10 \mathrm{~mL}$ of $100 \%$ ethanol, and distilled water was added to prepare a $100 \mathrm{mM}$ stock solution. The control was prepared without 
furfural and HMF. The assays were performed on a shaker at $32^{\circ} \mathrm{C}$ and $180 \mathrm{rpm}$ for $60 \mathrm{~h}$ using $250-\mathrm{mL}$ Erlenmeyer flasks filled with $50 \mathrm{~mL}$ of the above media. Samples were periodically removed every $12 \mathrm{~h}$ to estimate the furfural and HMF concentrations as well as cell growth.

\section{Fermentation profile of C. maltosa in the xylose mother liquor}

The C. maltosa inoculum was prepared by transferring cells from the maintenance medium (maltose extract agar) to a $50-\mathrm{mL}$ test tube containing $15 \mathrm{~mL}$ of YPD medium (consisting of $10 \mathrm{~g} \mathrm{~L}^{-1}$ yeast extract, $5 \mathrm{~g} \mathrm{~L}^{-1}$ tryptone, and $10 \mathrm{~g} \mathrm{~L}^{-1}$ dextrose). Incubation was carried out at $32^{\circ} \mathrm{C}$ and $200 \mathrm{rpm}$ for $24 \mathrm{~h}$. The cells were recovered by centrifugation and transferred to a $250-\mathrm{mL}$ Erlenmeyer flask containing $50 \mathrm{~mL}$ of medium (consisting of $15 \mathrm{~g} \mathrm{~L}^{-1}$ yeast extract and $200 \mathrm{~g} \mathrm{~L}^{-1}$ xylose mother liquor, pH 5.5 (autoclaved at $105^{\circ} \mathrm{C}$ for $15 \mathrm{~min}$ )). The medium was cultivated at $200 \mathrm{rpm}$ and $32^{\circ} \mathrm{C}$ for $60 \mathrm{~h}$. Samples were periodically removed at 12 -h intervals, and the concentrations of glucose, L-arabitol, and xylitol were determined.

\section{Xylose enrichment from xylose mother liquor using $C$. maltosa and $B$. subtilis strain BSxyl}

Fermentation medium (containing $15 \mathrm{~g} \mathrm{~L}^{-1}$ yeast extract and $200 \mathrm{~g} \mathrm{~L}^{-1}$ xylose mother liquor) was first treated with yeast $C$. maltosa cells to remove glucose and the inhibitors, as described above. Recombinant B. subtilis BSxyl was first cultivated in $5 \mathrm{~mL}$ of LB medium at $37^{\circ} \mathrm{C}$ and then transferred to $40 \mathrm{~mL}$ of detoxified fermentation medium. The culture was incubated overnight at $37^{\circ} \mathrm{C}$ with shaking at $200 \mathrm{rpm}$. It was then transferred to $360 \mathrm{~mL}$ of detoxified fermentation medium in a 2 -L flask at $37^{\circ} \mathrm{C}$ and shaken at $200 \mathrm{rpm}$ for $12 \mathrm{~h}$ to obtain $400 \mathrm{~mL}$ of second-class seed. This 400-mL seed culture was transferred to a 5-L fermentor containing $4 \mathrm{~L}$ of detoxified fermentation medium in order to enrich xylose by depleting L-arabinose and some of the galactose present. Samples were taken at regular intervals and analyzed by HPLC to determine the content and relative purity of xylose. Fermentation was completed when the L-arabinose in the medium was completely exhausted. The xylose-enriched clear fermentation broth was obtained by centrifugation. Yeast C. maltosa cells were added to the broth to synthesize xylitol, as described below.

\section{Model sugar studies}

To evaluate the influence of the sugar components of the xylose mother liquor on the growth of B. subtilis strain BSxyl in the absence of inhibitors, this strain was cultured in $250-\mathrm{mL}$ shake flasks containing $50 \mathrm{~mL}$ of the model sugars medium. This medium consisted of $10 \mathrm{~g} \mathrm{~L}^{-1}$ yeast extract and the following model sugars: $70 \mathrm{~g} \mathrm{~L}^{-1}$ xylose, $30 \mathrm{~g} \mathrm{~L}^{-1} \mathrm{~L}$-arabinose, $16 \mathrm{~g} \mathrm{~L}^{-1}$ glucose, $16 \mathrm{~g} \mathrm{~L}^{-1}$ galactose, $2 \mathrm{~g} \mathrm{~L}^{-1}$ mannose, $2 \mathrm{~g} \mathrm{~L}^{-1}$ rhamnose, and $2 \mathrm{~g} \mathrm{~L}^{-1}$ oligoxylosaccharide. The DS content was $130 \mathrm{~g} \mathrm{~L}^{-1}$ in $20 \%$ xylose mother liquor. The cells were incubated for $60 \mathrm{~h}$ at $37^{\circ} \mathrm{C}$ on a rotary shaker at 200 rpm.

\section{Reduction of xylose to xylitol by transformation with the yeast C. maltosa}

The xylose-enriched clear supernatant, obtained as described above, was concentrated to a xylose content of $250 \mathrm{~g} \mathrm{~L}^{-1}(\mathrm{w} / \mathrm{v})$. Different concentrations of C. maltosa, ranging from 30 to $60 \mathrm{~g} \mathrm{~L}^{-1}$ dry weight of cells $(1 \mathrm{~mL}$ cell suspension with an $\mathrm{OD}_{600}$ value of 1 was equivalent to $0.30 \mathrm{mg}$ dry weight of C. maltosa) and obtained from the stage after the removal of inhibitors, were suspended in the xylose concentrate and used to reduce xylose to xylitol. Samples were withdrawn at regular intervals and assayed. After the reduction of xylose to xylitol, a clear transformation broth was obtained by centrifugation, and it was treated with ion-exchange resins to reduce its conductivity to less than $100 \mu \mathrm{s} \mathrm{cm}^{-1}$. Activated charcoal was used to obtain a colorless solution, which was then concentrated by rotary vacuum evaporation at $65^{\circ} \mathrm{C}$. This increased the xylitol content to $800 \mathrm{~g} \mathrm{~L}^{-1}$.

\section{Preparation of xylitol crystals}

Xylitol seed was added to the colorless solution containing $800 \mathrm{~g} \mathrm{~L}^{-1}$ xylitol at $65^{\circ} \mathrm{C}$ to increase the supersaturation, and the solution was then transferred to a $10-\mathrm{L}$ crystallizer that was subjected to linear cooling from $65^{\circ}$ $\mathrm{C}$ to $15^{\circ} \mathrm{C}$ in $50 \mathrm{~h}$ (one degree decrease per hour) with simultaneous (periodic) stirring. Xylitol crystals were separated from the crystallization mass by centrifugation. The resulting xylitol mother liquor was further concentrated to $800 \mathrm{~g} \mathrm{~L}^{-1}$ by rotary vacuum evaporation at $65^{\circ} \mathrm{C}$ and then subjected to crystallization under the same conditions. Generally, xylitol can be crystallized three times from the above purified colorless solution.

\section{Analytical methods}

The concentrations of sugar and sugar alcohols were determined using an HPLC system equipped with a Shodex RI 101 refractive index detector and an analytical Shodex SPO 810 sugar column $\left(8 \times 30 \mathrm{~mm}, \mathrm{~Pb}^{2+}\right.$ cation exchange column). A sample $(50 \mu \mathrm{L})$ was injected into the HPLC system and eluted with distilled water at a column temperature of $70^{\circ} \mathrm{C}$ and a flow rate of $1.2 \mathrm{~mL}$ $\mathrm{min}^{-1}$. The absorbance at $280 \mathrm{~nm}\left(A_{280}\right)$ was an indicator of the concentration of the inhibitors (furfural or HMF) in the medium because these inhibitors have maximum absorbance at $280 \mathrm{~nm}$. 


\section{Results and discussion}

Identification of the recombinant $B$. subtilis strain BSxyl

To determine whether the $\mathrm{Cm}$ gene was inserted into the chromosome of B. subtilis strain BSxyl at the xylose isomerase gene locus, two sets of primers were used to amplify the corresponding DNA with genomic DNA as the template. Two DNA fragments of size $1.4 \mathrm{~kb}$ were amplified with the two sets of primers and the recombinant strain B. subtilis BSxyl genomic DNA, whereas no DNA bands were amplified when the nonrecombinant strain's genomic DNA was used as the template (Figure 2A). This indicated that the $\mathrm{Cm}$ gene was inserted at the locus of the xylose isomerase gene.
To determine whether the xylose isomerase gene was inactivated by $\mathrm{Cm}$ gene insertion, xylose-to-xylulose enzymatic conversion assays were conducted using crude cell extracts as the enzyme solution. The HPLC analysis (Figure 2B) revealed that strain BSxyl did not have any active xylose isomerase and was therefore unable to transform xylose to D-xylulose. In contrast, the crude extract from nonrecombinant B. subtilis 168 could convert xylose to D-xylulose.

Additionally, the recombinant B. subtilis strain BSxyl and nonrecombinant one were cultured in LB medium containing $10 \mathrm{~g} \mathrm{~L}^{-1}$ xylose, as described in Methods and Materials. Throughout the 24-h cultivation period, the

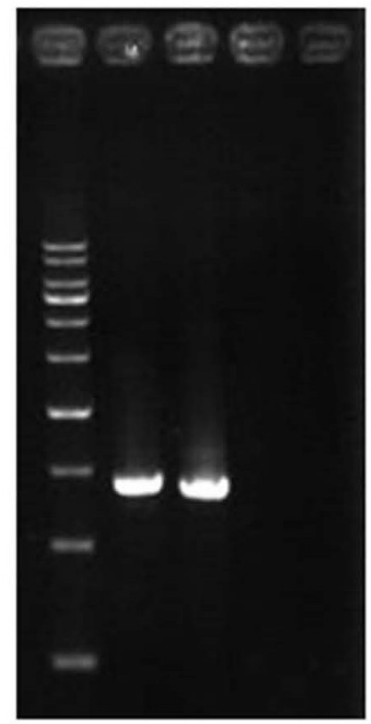

A

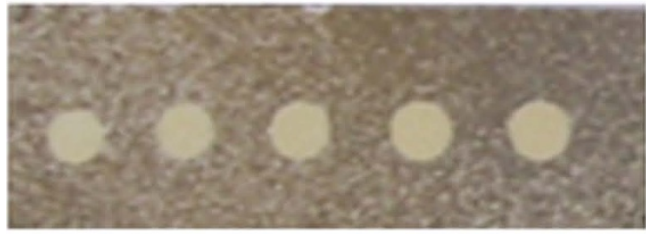

123

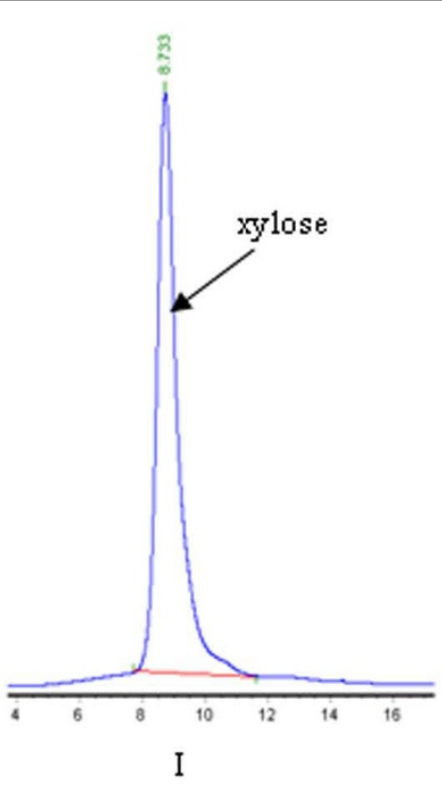

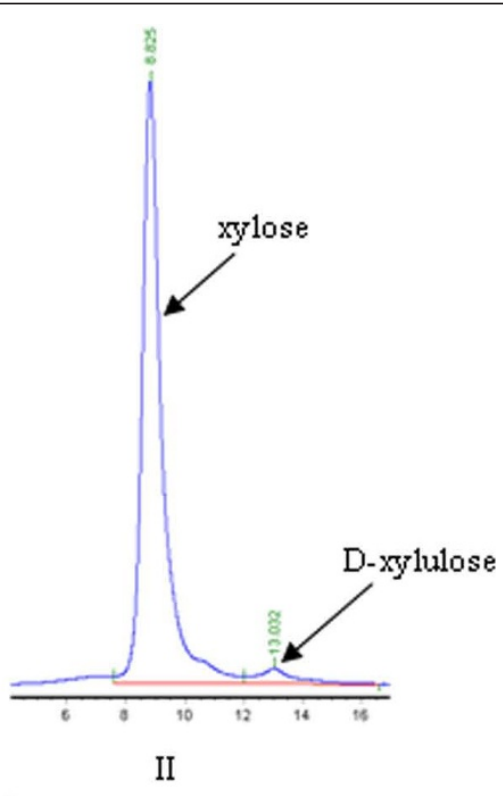

B

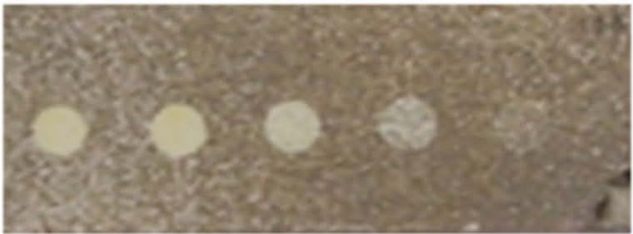

$\begin{array}{lllll}1 & 2 & 3 & 4 & 5\end{array}$

Figure 2 Identification of recombinant B. subtilis carrying the xylose isomerase gene disruption. A, PCR identification of two recombinant B. subtilis strains carrying the xylose isomerase gene disruption (lanes 1 and 2) and two wild-type B. subtilis strains (lanes 3 and 4). To create the recombinant strains, the 1.4-kb DNA was amplified using two sets of primers (see Method and Materials); B, HPLC analysis of the xylose isomeric reaction. The xylose isomeric reaction with the crude extract from strain BSxyl (xylA disrupted); DNA markers from the bottom of the gel are in the following order: $500 \mathrm{bp}, 1 \mathrm{~kb}, 1.5 \mathrm{~kb}$, and $2 \mathrm{~kb}$. B, HPLC analysis of the xylose isomeric reaction with the crude extract from recombinant (I) and wild-type B. subtilis 168 (II). No D-xylulose was detected after incubation with the crude extract from the $x y / A$-gene-disrupted strain BSxyl (I), while D-xylulose could be detected using the crude extract from the control strain B. subtilis 168 as enzyme and xylose as substrate (II). C, TLC assay of the culture medium of recombinant BSxyl (i) and B. subtilis 168 (ii). The culture medium consisted of $L B$ and $10 \mathrm{~g} \mathrm{~L}^{-1} \mathrm{xylose}$. The spot in 1 represents $1 \mu \mathrm{L}$ of $10 \mathrm{~g} \mathrm{~L}^{-1}$ xylose standard, and the spots in 2, 3, 4, and 5 show $1 \mu \mathrm{L}$ of each sample taken at 0, 8, 16, and 24 h. 
xylose content remained almost constant for B. subtilis BSxyl, while it decreased in the control strain B. subtilis 168 , indicating that strain BSxyl was almost unable to utilize xylose after disruption of the xylose isomerase gene. After incubation for $24 \mathrm{~h}$, the xylose content of the BSxyl recombinant strain culture was $9.24 \mathrm{~g} \mathrm{~L}^{-1}$, as calculated by the integration of the HPLC peaks, while that of the control strain was $3.45 \mathrm{~g} \mathrm{~L}^{-1}$. The TLC assay further proved that the recombinant B. subtilis strain BSxyl could not utilize xylose. When samples taken from the medium at $0,8,16$, and $24 \mathrm{~h}$ were applied to the silica gel plate, the brightness of the spot for strain BSxyl remained unchanged, while that of the spot for the control strain decreased (Figure 2C). Thus, the genetically modified $B$. subtilis strain in which the xylose isomerase gene was disrupted could not utilize xylose but could utilize glucose, L-arabinose and to a lesser extent galactose. Galactose is not actively transported into B. subtilis 168. Even low amounts of internal UDPgalactose are toxic for galE-negative B. subtilis strains [13]. B. subtilis 168 cannot grow on galactose or xylose as the sole carbon source due to its inability to transport these sugars from the outside to the inside of the cell [14]. However, B. subtilis can use D-galactose and $\mathrm{D}$-xylose as carbon sources when L-arabinose, the inducer of monosaccharide transporter protein (AraE) synthesis, is added to the growth medium $[15,16]$. B. subtilis can also grow on L-arabinose as the sole carbon and energy source. The ability to utilize L-arabinose depends on the presence of three intracellular enzymes encoded by the $\operatorname{ara\mathrm {A}}$ (L-arabinose isomerase), araB (L-ribulokinase), and araD (L-ribulose-5-phosphate-4-epimerase) genes, which sequentially convert L-arabinose to L-ribulose, L-ribulose-5-phosphate, and D-xylulose-5-phosphate, respectively. D-Xylulose-5-phosphate is further catabolized through the pentose phosphate pathway [17]. BSxyl first utilizes glucose and then utilizes L-arabinose which then induces the AraE protein to transport xylose and galactose into the cell cytoplasm.

The xylose mother liquor contains $150 \mathrm{~g} \mathrm{~L}^{-1} \mathrm{~L}$-arabinose as well as $350-400 \mathrm{~g} \mathrm{~L}^{-1}$ xylose. Although C. maltosa used in this study could spontaneously and efficiently reduce xylose and L-arabinose to xylitol and $\mathrm{L}$-arabitol, it is very difficult to separate xylitol due to the presence of $\mathrm{L}$-arabitol which greatly reduces the crystallization efficiency of xylitol. An alternative method would be to remove L-arabinose from the xylose mother liquor, prior to the latter's use as a raw material for the reduction of xylose to xylitol by yeast cells. Recombinant B. subtilis BSxyl could utilize L-arabinose but not xylose; therefore, these cells could be used to deplete L-arabinose and enrich xylose in the xylose mother liquor. As a result, L-arabitol was not produced during yeast transformation using the xylose mother liquor as the raw material; this facilitated the crystallization of xylitol and improved the purity of the xylitol obtained from the yeast transformation medium.

\section{Removal of inhibitors by C. maltosa}

It has been shown that furfural and HMF have maximum absorbance at $280 \mathrm{~nm}\left(A_{280}\right)$. Since no other proteins were detected in the xylose mother liquor, the $A_{280}$ value could be used as an indicator of the content of furfural and HMF [18]. These two compounds are the main inhibitors present in the xylose mother liquor. We obtained the following relationship between the furfural or HMF concentration and the $A_{280}$ value: $\mathrm{C}_{\text {(furfural) }}$ $=0.732+60.49 \times A_{280}, \mathrm{C}_{(\mathrm{HMF})}=0.603+49.62 \times A_{280}$. The $R^{2}$ value was 0.9994 and 0.9997 , respectively. $C$ represents the concentration of furfural or HMF $(\mu \mathrm{M})$, and $A_{280}$ is the absorbance at $280 \mathrm{~nm}$. A $100-\mu \mathrm{L}$ aliquot of $C$. maltosa cells in the exponential phase cultivated in YPD medium was transferred to $25 \mathrm{~mL}$ of fresh YNB medium containing various concentrations of furfural or HMF (see Method and Material). Each culture was inoculated with the same cell concentration $\left(\mathrm{OD}_{600}\right.$ at 0.13 ), and the ability of the cells to grow was determined by monitoring the cell densities at $\mathrm{OD}_{600}$ over a period of $60 \mathrm{~h}$. The $A_{280}$ was also monitored to determine the concentration of total inhibitors (furfural and HMF). As shown in Table 3, no significant decrease in growth was observed for $C$. maltosa cultivated in medium containing 5-20 mM furfural or HMF over $60 \mathrm{~h}$. In comparison to cells cultivated in medium without furfural or HMF, the growth of C. maltosa was inhibited by about $25 \%$ and $50 \%$ in the presence of $30 \mathrm{mM}$ furfural or $40 \mathrm{mM} H \mathrm{HMF}$, respectively, over a period of $60 \mathrm{~h}$. No significant decrease in growth was observed at furfural or HMF concentrations less than $20 \mathrm{mM}$; consequently, no differences were observed in the lag times and doubling times of C. maltosa. However, in the presence of $30 \mathrm{mM}$ furfural or $40 \mathrm{mM}$ HMF, the lag times and doubling times were longer (data not shown). The ability of C. maltosa to metabolize furfural or HMF was also tested by monitoring the $A_{280}$. The $A_{280}$ value decreased to less than 0.05 from 81.4, 162.8, and 325.6, which corresponded to 5,10 , and $20 \mathrm{mM}$ of furfural or HMF, respectively, over a period of $36 \mathrm{~h}$. This indicated that $C$. maltosa could metabolize furfural or HMF in $36 \mathrm{~h}$. Although C. maltosa showed longer lag times and doubling times as well as $25 \%-50 \%$ growth inhibition at $30 \mathrm{mM}$ and $40 \mathrm{mM}$ furfural or HMF, the $A_{280}$ value also decreased to less than 0.05 from 488.4 and 651.2 after $60 \mathrm{~h}$ of cultivation. These results indicated that yeast C. maltosa can efficiently metabolize inhibitors such as furfural or HMF. The total concentration of furfural and HMF in the xylose mother liquor was approximately $40 \mathrm{mM}$, as calculated from the above formula. 
Table 3 The growth profile $\left(O D_{600}\right)$ and removal of inhibitors $\left(A_{280}\right)$ of $C$. maltosa from YNB medium containing various concentrations of furfural or HMF

\begin{tabular}{|c|c|c|c|c|c|c|c|c|c|c|c|c|c|}
\hline \multirow[t]{2}{*}{ Conc. (mM) } & & \multicolumn{6}{|c|}{ Furfural } & \multicolumn{6}{|c|}{ HMF } \\
\hline & & $\mathrm{Oh}$ & $12 \mathrm{~h}$ & $24 \mathrm{~h}$ & $36 \mathrm{~h}$ & $48 \mathrm{~h}$ & $60 \mathrm{~h}$ & Oh & $12 \mathrm{~h}$ & $24 \mathrm{~h}$ & $36 \mathrm{~h}$ & $48 \mathrm{~h}$ & $60 \mathrm{~h}$ \\
\hline \multirow[t]{2}{*}{0} & $\mathrm{OD}_{600}$ & 0.13 & 3.35 & 7.32 & 12.4 & 14.6 & 16.2 & 0.13 & 3.76 & 8.96 & 13.4 & 15.4 & 16.6 \\
\hline & $A_{280}$ & 0.003 & 0.002 & 0.003 & 0.003 & 0.002 & 0.003 & 0.002 & 0.002 & 0.002 & 0.003 & 0.002 & 0.002 \\
\hline \multirow[t]{2}{*}{5} & $\mathrm{OD}_{600}$ & 0.13 & 3.42 & 7.89 & 13.6 & 15.6 & 17.6 & 0.13 & 3.45 & 7.98 & 13.6 & 14.8 & 16.8 \\
\hline & $A_{280}$ & 81.4 & 35.6 & 0.05 & 0.006 & & & 81.4 & 40.2 & 0.09 & 0.004 & & \\
\hline \multirow[t]{2}{*}{10} & $\mathrm{OD}_{600}$ & 0.13 & 3.25 & 7.22 & 12.6 & 14.4 & 16.0 & 0.13 & 3.24 & 7.26 & 12.4 & 13.6 & 15.8 \\
\hline & $A_{280}$ & 162.8 & 122.4 & 62.4 & 0.005 & & & 162.8 & 132.4 & 60.6 & 0.005 & & \\
\hline \multirow[t]{2}{*}{20} & $\mathrm{OD}_{600}$ & 0.13 & 3.02 & 6.86 & 12.0 & 13.2 & 15.4 & 0.13 & 3.12 & 6.82 & 11.2 & 12.6 & 14.6 \\
\hline & $A_{280}$ & 325.6 & 290.2 & 128.4 & 0.05 & & & 325.6 & 270.6 & 110.4 & 0.05 & & \\
\hline \multirow[t]{2}{*}{30} & $\mathrm{OD}_{600}$ & 0.13 & 1.86 & 5.20 & 9.68 & 10.6 & 12.6 & 0.13 & 1.68 & 4.94 & 8.86 & 9.84 & 11.8 \\
\hline & $A_{280}$ & 488.4 & 440 & 363.2 & 220.6 & 120.3 & 0.05 & 488.4 & 405.6 & 368.4 & 282.4 & 144.4 & 0.05 \\
\hline \multirow[t]{2}{*}{40} & $\mathrm{OD}_{600}$ & 0.13 & 0.78 & 2.66 & 4.24 & 6.64 & 8.60 & 0.13 & 0.86 & 3.06 & 5.46 & 7.14 & 8.86 \\
\hline & $A_{280}$ & 651.2 & 545.2 & 410.2 & 330.4 & 150.6 & 0.05 & 651.2 & 520.6 & 443.6 & 308.2 & 163.4 & 0.05 \\
\hline
\end{tabular}

For details, see Methods and Materials. Values are the means of two dependent experiments.

Thus, C. maltosa could be used to detoxify the xylose mother liquor and remove inhibitors such as furfural and HMF, which were formed by the dehydration of released sugars (xylose and glucose) from corncobs or sugarcanes pretreated with dilute acid. The $A_{280}$ value also decreased to less than 0.05 from 135.6 when C. maltosa cells were cultivated in medium containing $200 \mathrm{~g} \mathrm{~L}^{-1}$ xylose mother liquor and $20 \mathrm{~g} \mathrm{~L}^{-1} \mathrm{YNB}$ for 36 $\mathrm{h}$ at $33^{\circ} \mathrm{C}$ and $200 \mathrm{rpm}$. Interestingly, no xylitol accumulation was observed during the bio-detoxification and glucose depletion process (data not shown). There are many literatures reported that furfural or HMF in undetoxified lignocellulose could act as external electron acceptors, thus repress the xylitol production in lignocellulose fermentation by yeast strains $[19,20]$. For corncob hydrolysate which contains less furfural than softwood hydrolysates, xylitol could be accumulated in the fermentation medium [21]. Whereas xylose mother liquor used in this study contains about $40 \mathrm{mM}$ furfural and HMF, which could inhibit xylitol formation during the first treatment by $C$. maltosa. The mechanism by which furfural and HMF are degraded in Saccharomyces cerevisiae has been clarified in detail and involves multiple genes including those encoding NAD $(\mathrm{P}) \mathrm{H}$-dependent aldehyde reductases and alcohol dehydrogenases which reduce furfural and HMF to less cytotoxic alcohols [22-24]. More recently, the alcohol dehydrogenase genes $(\mathrm{CmADHs})$ from C. maltosa were cloned and were functionally identified to play a critical role to maintain NADH/NAD ratio, which might closely relate to detoxifying furfural and HMF [12,22]. During the biodetoxification of xylose mother liquor by C. maltosa, $\mathrm{NAD}(\mathrm{P}) \mathrm{H}$ produced by depletion of glucose might be acted as cofactors to reduce furfural and HMF to alchols but not reduce xylose to xylitol, resulting no xylitol production during the first treatment with C. maltosa. Whether the degradation mechanism in C. maltosa is the same as that in $S$. cerevisiae is still under investigation.

\section{Enrichment of xylose by C. maltosa and B. subtilis BSxyl}

B. subtilis strain BSxyl showed poor growth when it was inoculated into a fermentation medium containing $20 \%$ xylose mother liquor and $1.5 \%$ yeast extract and cultured at $37^{\circ} \mathrm{C}$ and $200 \mathrm{rpm}$. This is probably due to the high amounts of inhibitory compounds ( $8 \mathrm{mM}$ furfural and HMF in $20 \%$ xylose mother liquor) present in the culture medium. In contrast, this microorganism grew well in the same fermentation medium detoxified with C. maltosa and in the model sugar medium (data not shown). These results indicated that furfural and HMF present in the xylose mother liquor can inhibit the growth of B. subtilis strain BSxyl. Moreover, C. maltosa could degrade these inhibitory compounds and exhaust all the glucose in the xylose mother liquor (Figure 3, A and $3 \mathrm{~B}$ ), thereby eliminating the carbon catabolite repression of $B$. subtilis [25] and accelerating the metabolism of L-arabinose. After detoxification of the medium by $C$. maltosa, B. subtilis strain BSxyl grew well in the fermentation medium containing $20 \%$ xylose mother liquor and $1.5 \%$ yeast extract. The L-arabinose and galactose contents decreased with the fermentation time, while the xylose content remained constant during fermentation. After $60 \mathrm{~h}$ of cultivation, $\mathrm{L}$-arabinose was completely depleted (Figure 3, C), while the xylose content $(70 \mathrm{~g} / \mathrm{L}$ of xylose) remained almost the same as that at the beginning of fermentation. Due to the strain's poor ability to utilize galactose, a small amount of residual galactose was also detected in the fermentation medium after fermentation (Figure 3, D, lane 2) by TLC 


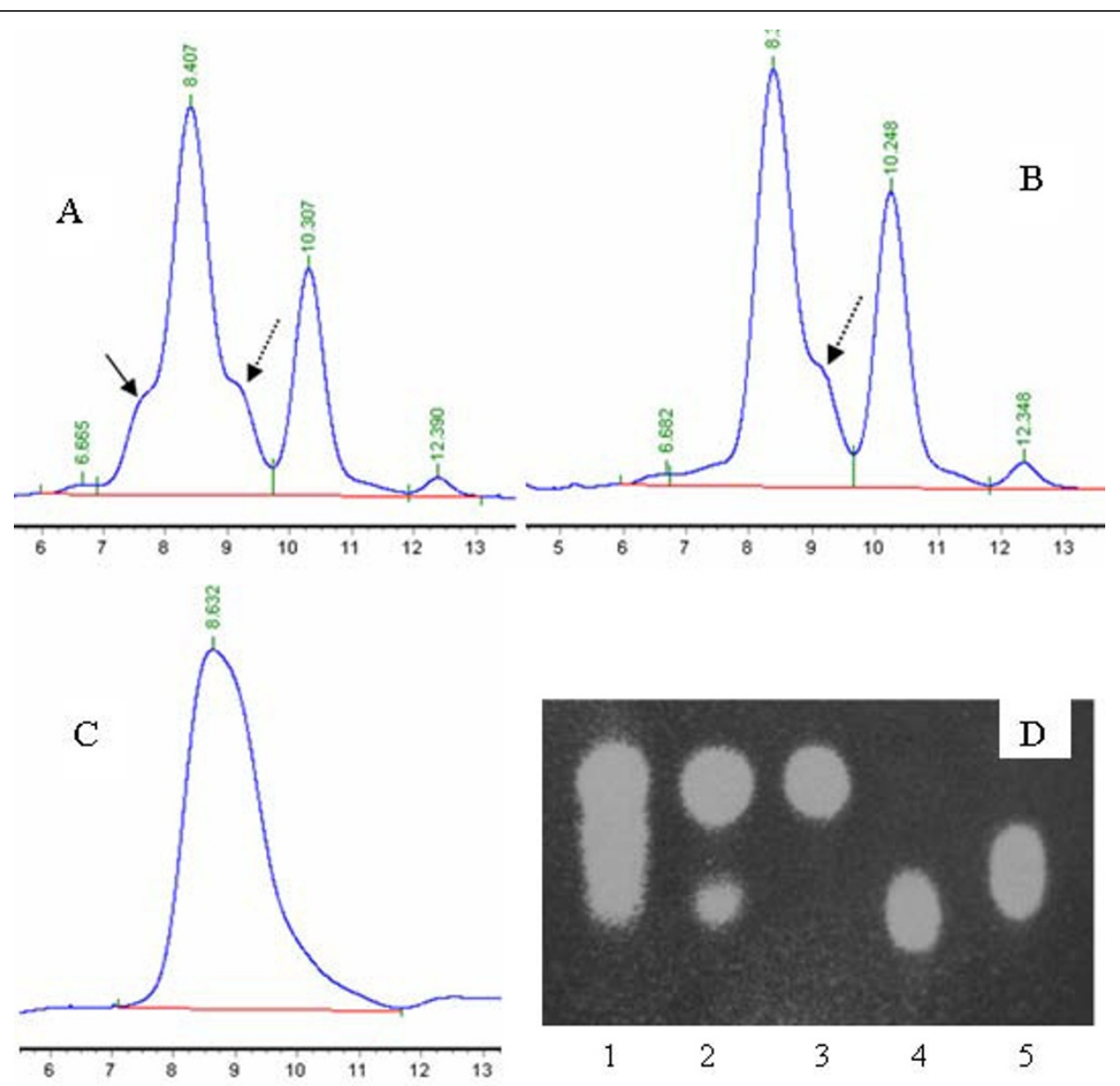

Figure 3 HPLC and TLC analyses of the xylose mother liquor treated with C. maltosa and B. subtilis strain BSxyl. A, xylose mother liquor containing glucose (showed by solid line), xylose (8.407 min), galactose (showed by dotted line), L-arabinose (10.307 min), and unknown sugars ( 6.665 min and $12.390 \mathrm{~min}$ ); B, xylose mother liquor treated with C. maltosa for $12 \mathrm{~h}$ (glucose is depleted); C, B. subtilis strain BSxyl was inoculated in xylose mother liquor pretreated with C. maltosa for $60 \mathrm{~h}$. L-arabinose as well as some galactose and unknown sugars (6.682 min and $12.348 \mathrm{~min}$ ) were depleted. D, TLC analysis of the B. subtilis strain BSxyl final fermentation medium (C) to detect whether galactose is still present. Lane 1, xylose mother liquor; lane 2, B. subtilis strain BSxyl final fermentation medium (C); lanes 3 to5, xylose, galactose, and L-arabinose standards, respectively.

analysis. The purity of xylose plus trace amounts of Dgalactose in the fermentation broth was as high as $85 \%$ (data not shown).

\section{Biological synthesis of xylitol from the xylose-enriched fermentation broth using $C$. maltosa}

Microbial reduction of the xylose-enriched broth by B. subtilis BSxyl was performed using C. maltosa cells as the biocatalyst, and $213 \mathrm{~g} \mathrm{~L}^{-1}$ xylitol was obtained from the medium containing $250 \mathrm{~g} \mathrm{~L}^{-1}$ xylose over a period of $50 \mathrm{~h}$. The volumetric productivity of xylitol was $4.25 \mathrm{~g} \mathrm{~L}^{-1}$ $\cdot \mathrm{h}^{-1}$, and the conversion yield was $0.85 \mathrm{~g}$ xylitol per $\mathrm{g}$ xylose. The volumetric productivity of xylitol was shown to be closely related to the cell concentration, with increased productivity resulting from an increased initial cell concentration [26]. The volumetric productivity and specific productivity of xylitol were $4.25 \mathrm{~g} \mathrm{~L}^{-1} \mathrm{~h}^{-1}$ and 0.85 g xylitol per g xylose, respectively, over $50 \mathrm{~h}$ when $30 \mathrm{~g} \mathrm{~L}^{-1}$ dry weight of cells was used at $1.0 \mathrm{vvm}$ aeration and 200 rpm stirrer speed in a 5 - $\mathrm{L}$ fermentor. The fermentation time was reduced to $28 \mathrm{~h}$ by increasing the initial cell concentration to $50 \mathrm{~g} \mathrm{~L}^{-1}$ in the same transformation medium and under the same conditions. The volumetric productivity was $7.5 \mathrm{~g} \mathrm{~L}^{-1} \cdot \mathrm{h}^{-1}$, and the specific productivity was 0.82 g xylitol per $g$ xylose. From the results, we concluded that higher volumetric productivity was achieved when a higher cell concentration was used. Although the volumetric productivity increased, the specific productivity remained almost constant, regardless of the initial cell concentration. Interestingly, in addition to glycerol and ethanol, the yeast produced $\mathrm{D}$-arabitol as a by-product from xylose (Figure 4, A and 4B). The glycerol level rapidly 


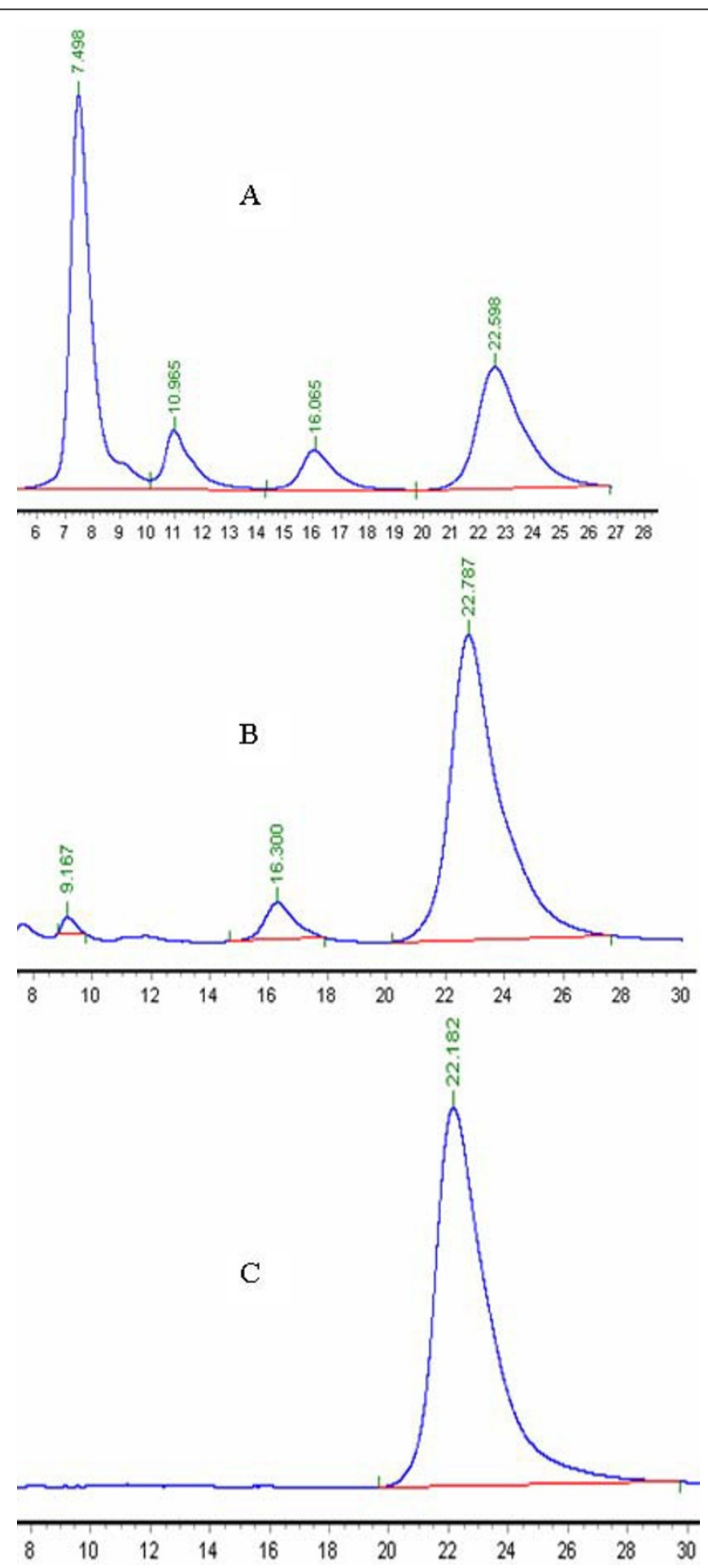

Figure $4 \mathrm{HPLC}$ analysis of the biotransformation of xylose to xylitol by C. maltosa and of crystallized xylitol from the biotransformation broth. A, biotransformation of xylose to xylitol by C. maltosa for 24 h; B, 50 h; C, crystallized xylitol from the

biotransformation broth. Vertical arrow in A at 9.167 min represents ethanol, and that at $10.965 \mathrm{~min}$ in A indicates glycerol. Similarly, the arrow at $16.065 \mathrm{~min}$ in A and 16.300 min in B represent D-arabitol and that at 22 min in A, B, and C indicates xylitol. 
decreased throughout the culture period, from $7.25 \mathrm{~g} \mathrm{~L}^{-1}$ at $24 \mathrm{~h}$ to less than $1 \mathrm{~g} \mathrm{~L}^{-1}$ at $50 \mathrm{~h}$, but the D-arabitol and ethanol levels decreased very slowly, from $5.26 \mathrm{~g} \mathrm{~L}^{-1}$ and $2.42 \mathrm{~g} \mathrm{~L}^{-1}$ at $24 \mathrm{~h}$ to $5.02 \mathrm{~g} \mathrm{~L}^{-1}$ and $2.34 \mathrm{~g} \mathrm{~L}^{-1}$ at $50 \mathrm{~h}$, respectively. Figure 5 shows a possible pathway for the conversion of xylose to D-arabitol, glycerol, and ethanol. $\mathrm{D}$-arabitol was secreted into the medium and could be detected by HPLC when xylitol (ranging from 50 to $200 \mathrm{~g}$ $\mathrm{L}^{-1}$ ) was used as the substrate. However, no xylitol was detected in the medium when $\mathrm{D}$-arabitol was used as the substrate (50-200 $\mathrm{g} \mathrm{L}^{-1}$ ) (data not shown). These results indicate that $\mathrm{D}$-xylulose was reduced to $\mathrm{D}$-arabitol by D-xylulose reductase, which catalyzes the irreversible reaction from D-xylulose to D-arabitol. On the other hand, Darabitol was oxidized to D-ribulose by $\mathrm{D}$-arabitol dehydrogenase and was converted to D-ribulose-5-P, which then entered the pentose phosphate pathway. Xylitol was crystallized from the purified xylitol-enriched solution, and its purity reached $99.5 \%$. No D-arabitol was detected by HPLC analysis (Figure 4, C).

Recently, Candida yeasts, particularly C. tropicalis, C. guilliermondii, and C. parapsilosis, have been extensively studied for their possible applications to the production of xylitol from pure xylose or xylose-containing hydrolysates such as sugarcane bagasse or corn cob hydrolysates $[4,18,27]$. Some of their favorable properties include their high xylitol yields from xylose [28] and their excellent adaptability [4,29]. Although C. tropicalis, C. guilliermondii, and C. parapsilosis could grow on media containing high concentrations of pure xylose $\left(250 \mathrm{~g} \mathrm{~L}^{-1}\right)$ and produce xylitol with specific productivity ranging from 0.65 to $0.78 \mathrm{~g} / \mathrm{g}$ xylose, these three yeasts grew poorly in media containing $300 \mathrm{~g} \mathrm{~L}^{-1}$ xylose mother liquor and furfural was showed to be a strong inhibitor of their growth even at a concentration of $0.2 \%$ [30,31]. However, C. maltosa used in this study could grow well on the same medium (data not shown). Thus, C. maltosa showed the best tolerance to high concentrations of the xylose mother liquor. Based on these properties, C. maltosa was selected in this study to remove the inhibitory compounds furfural and HMF as well as glucose from xylose mother liquor. L-arabinose was subsequently removed by $B$. subtilis Bsxyl, leading to the enrichment of xylose, which was then reduced to xylitol by $C$. maltosa cells. The C. maltosa cells used in the last step were the same as those used in the first step for detoxification and removal of glucose from the xylose mother liquor.

Large quantities of C. maltosa cells were obtained during the detoxification and glucose removal process, and these could then be used as biocatalysts to efficiently reduce xylose to xylitol at high volumetric productivity ( $4.25 \mathrm{~g} \mathrm{~L}^{-1} \mathrm{~h}^{-1}$ to $7.5 \mathrm{~g} \mathrm{~L}^{-1} \mathrm{~h}^{-1}$, depending on the initial cell concentration) and $0.85 \mathrm{~g}$ xylitol/g

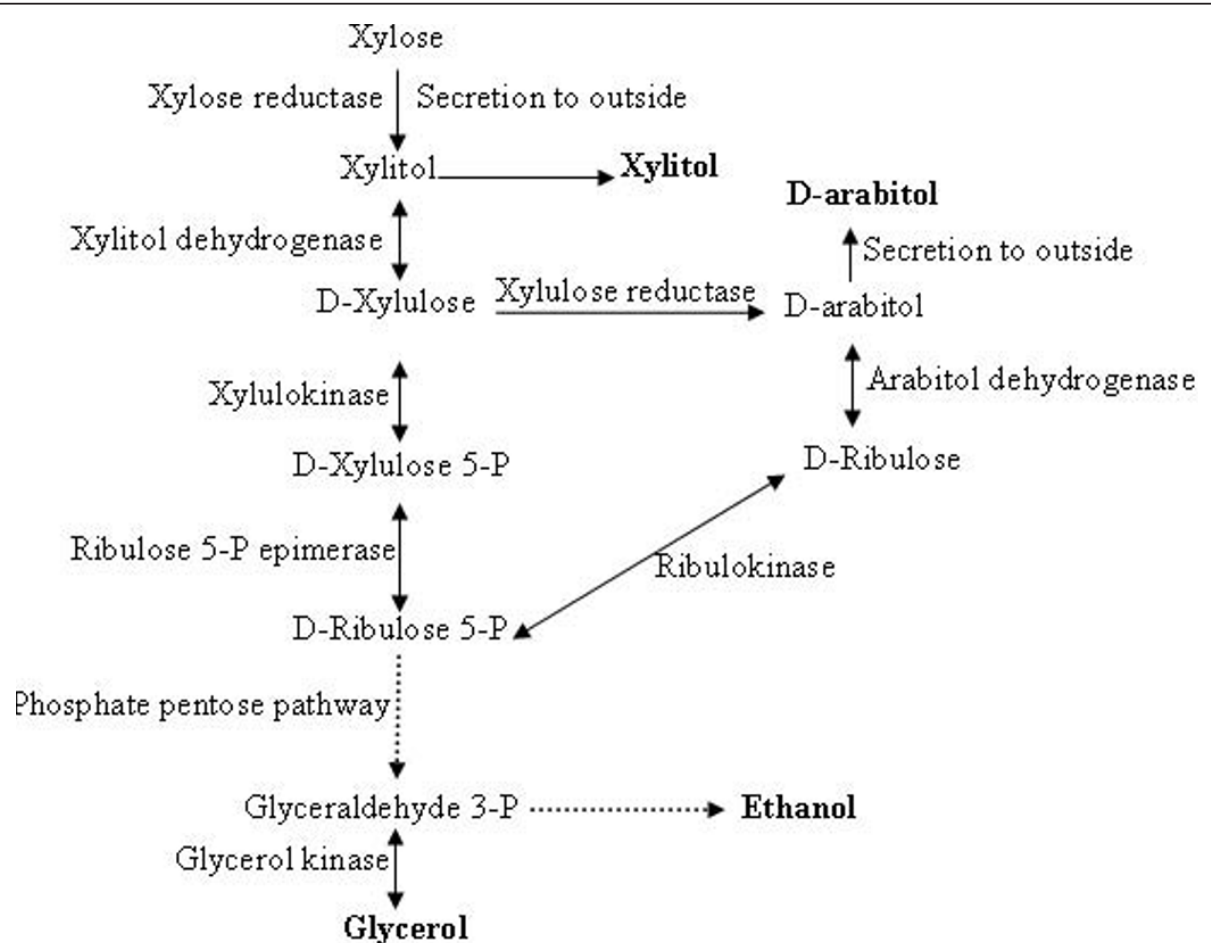

Figure 5 Possible pathways for the conversion of xylose to D-arabitol, glycerol, and ethanol by C. maltosa. Dotted arrow shows multiple reaction steps. 
xylose specific productivity. The yeast cells could be reused as biocatalysts, to reduce xylose to xylitol. Moreover, no tedious procedure was required to obtain the cells. Recently, many different yeast strains including their derivative recombinants were used as wholecell biocatalysis to convert substrates to their products. Employing yeast strains as whole-cell biocatalysts includes many advantages: Cofactors necessary for biocatalysis can be regenerated from cheap co-substrates (e.g. glucose) and are more stable within their natural cellular environment, whole cells can be employed for repetitive biocatalysis [32]. In this study, C. maltosa could be employed for at least 5 times without significant decrease in their efficiency and viability (data not shown). To our knowledge, this is the first attempt to apply this biotechnique for the production of xylitol from xylose mother liquor, which is a viscous and compositionally complex low-value by-product of the xylose production industry. Further studies on the feasibility of this novel strategy for the scaled-up preparation of xylitol from xylose mother liquor are currently underway.

\section{Conclusions}

The present work describes a novel strategy to efficiently purify and isolate pure crystallized xylitol, a more high-valued product, from low-cost material xylose mother liquor, which was sequentially treated with C. maltosa, B. subtilis Bsxyl, and C. maltosa again. Approximately, $70 \mathrm{~g} \mathrm{~L}^{-1}$ xylose of purity degree greater than $90 \%$ could be obtained from the initial fermentation medium containing $200 \mathrm{~g}$ xylose mother liquor (0.35 g xylose per g mother liquor) per liter medium after the removal of glucose and L-arabinose by C. maltosa and B. subtilis Bsxyl. In a 5-L fermentor using $C$. maltosa as whole-cell biocatalyst, the specific productivity was $0.82-0.85 \mathrm{~g}$ xylitol per $\mathrm{g}$ xylose, with varying volumetric productivity depending on cell concentration. $213 \mathrm{~g} \mathrm{~L}^{-1}$ xylitol was obtained from the medium containing $250 \mathrm{~g} \mathrm{~L}^{-1}$ xylose bio-purified from xylose mother liquor over a period of $50 \mathrm{~h}$.

\footnotetext{
Abbreviations

$A p^{r}$ : ampicillin resistance; $\mathrm{Cm}^{r}$ : chloramphenicol resistance; $\operatorname{trpC2}$ : auxotrophic mutant of tryptophan synthesis; BGSC: Bacillus Genetic Stock Center, Ohio State University; TLC: thin-layer chromatography; HMF: 5hydromethylfurfural; OD: optical density; xylA: xylose isomerase gene; xylB: xylulose kinase gene; xylR: regulator gene of xylose metabolism operon; EGTA: ethylene glycol bis(2-aminoethyl) tetraacetic acid; ATCC: America Type Collection Center; NADPH: nicotinamide adenine dinucleotide phosphate hydrogen; HPLC: high performance liquid chromatography; galE: UDPgalactose 4-epimerase; YNB: yeast nitrogen base; $A_{280}$ : absorbance at 280 $\mathrm{nm}$.
}

\section{Acknowledgements}

This work was supported by grants 973 and 863 from the Ministry of Science and Technology, the National Science Foundation of China,
Shanghai Leading Academic Discipline Project B203, and Guangxi Science Foundation Grant No.0832011.

\section{Author details}

${ }^{1}$ Laboratory of Microbial Metabolism and School of Life Sciences and Biotechnology, Shanghai Jiao Tong University, 800\# Dongchuan Road, Shanghai, China. ${ }^{2}$ Key Laboratory of Chemical and Biological Transforming Process, School of Chemistry and Ecology Engineering, Guangxi University for Nationalities, Nanning, China.

\section{Authors' contributions}

HRC and MGJ designed research; HRC and BW performed the plasmid construction and sugars and alcohols HPLC analysis; JYL performed the furfural and HMF degradation and fermentation experiments; SJL and ZXD provided advice on organizing the manuscript and on editorial quality; HRC and MGJ performed the literature review and drafted the manuscript. All authors have read and approved the final version of the manuscript.

\section{Competing interests}

The authors declare that they have no competing interests.

Received: 13 November 2010 Accepted: 7 February 2011 Published: 7 February 2011

\section{References}

1. Felipe MGA, Vitolo M, Mancilha IM, Silva SS: Fermentation of sugar cane bagasse hemicellulosic hydrolysate for xylitol production: effect of $\mathrm{pH}$. Biomass Bioenerg 1997, 13:11-14.

2. Rivas B, Domínguez JM, Domínguez H, Parajó JC: Bioconversion of posthydrolysed autohydrolysis liquors: an alternative for xylitol production from corn cobs. Enzyme Microb Technol 2002, 31:431-438.

3. Palmqvist $E$, Hagerdal B: Fermentation of lignocellulosic hydrolysates. II: inhibitors and mechanisms of inhibition. Bioresour Technol 2000, 74:25-33.

4. Rao RS, Jyothi CP, Prakasham RS, Sarma PN, Rao LV: Xylitol production from corn fiber and sugarcane bagasse hydrolysates by Candida tropicalis. Bioresour Technol 2006, 97:1974-1978.

5. Wierckx N, Koopman F, Bandounas L, de Winde JH, Ruijssenaars HJ: Isolation and characterization of Cupriavidus basilensis HMF14 for biological removal of inhibitors from lignocellulosic hydrolysate. Microbial Biotechnol 2010, 3:336-343.

6. Akinterinwa O, Khankal R, Cirino PC: Metabolic engineering for bioproduction of sugar alcohols. Curr Opin Biotechnol 2008, 19:461-467.

7. Green DH, Wakeley PR, Page A, Barnes A, Baccigalupi L, Ricca E, Cutting SM: Characterization of two Bacillus probiotics. Appl Environ Microbiol 1999, 65:4288-4291.

8. Bhavsar AP, Zhao X, Brown ED: Development and characterization of a xylose-dependent system for expression of cloned genes in Bacillus subtilis: conditional complementation of a teichoic acid mutant. Appl Environ Microbiol 2001, 67:403-410.

9. Modig T, Liden G, Taherzadeh M: Inhibition effects of furfural on alcohol dehydrogenase, aldehyde dehydrogenase and pyruvate dehydrogenase. Biochem J 2002, 363:769-776.

10. Kelly C, Jones O, Barnhart C, Lajoie C: Effect of furfural, vanillin and syringaldehyde on Candida guilliermondii growth and xylitol biosynthesis. Appl Biochem Biotech 2008, 148:97-108.

11. Allen SA, Clark W, McCaffery JM, Cai Z, Lanctot A, Slininger PJ, Liu ZL, Gorsich SW: Furfural induces reactive oxygen species accumulation and cellular damage in Saccharomyces cerevisiae. Biotechnol Biofuels 2010, 3:2.

12. Lin $Y$, He P, Wang $Q$, Lu D, Li Z, Wu C, Jiang N: The alcohol dehydrogenase system in the xylose-fermenting yeast Candida maltosa. PLOS ONE 2010, 5(7):e11752.

13. Krispin O, Allmansberger R: The Bacillus subtilis AraE protein displays a broad substrate specificity for several different sugars. J Bacteriol 1998, 180:3250-3252.

14. Lindner C, StÜlke J, Hecker M: Regulation of xylanolytic enzymes in Bacillus subtilis. Microbiology 1994, 140:753-757.

15. Sá-Nogueira I, Ramos SS: Cloning, functional analysis, and transcriptional regulation of the Bacillus subtilis araE gene involved in L-arabinose utilization. J Bacterio/ 1997, 179:7705-7711.

16. Krispin O, Allmansberger $R$ : The Bacillus subtilis galE gene is essential in the presence of glucose and galactose. J Bacteriol 1998, 180:2265-2270. 
17. Mota LJ, Tavares P, Sá-Nogueira I: Mode of action of AraR, the key regulator of L-arabinose metabolism in Bacillus subtilis. Mol Microbiol 1999, 33:476-489.

18. Tada K, Horiuchi Jl, Kanno T, Kobayashi M: Microbial xylitol production from corn cobs using Candida magnoliae. J Biosci Bioeng 2004, 98:228-230.

19. Wahlbom CF, Hahn-Hägerdal B: Furfural, 5-hydroxymethyl furfural, and acetoin act as external electron acceptors during anaerobic fermentation of xylose in recombinant Saccharomyces cerevisiae. Biotechnol Bioeng 2002, 78:172-178.

20. Karhumaa K, Sanchez RG, Hahn-Hägerdal B, Gorwa-Grauslund MF: Comparison of the xylose reductase-xylitol dehydrogenase and the xylose isomerase pathways for xylose fermentation by recombinant Saccharomyces cerevisiae. Microb Cell Fact 2007, 6:5.

21. Sedlak M, Ho NW: Production of ethanol from cellulosic biomass hydrolysates using genetically engineered Saccharomyce yeast capable of cofermenting glucose and xylose. Appl Biochem Biotechnol 2004, 113116:403-416.

22. Gorsich SW, Dien BS, Nichols NN, Slininger PJ, Liu ZL, Skory CD: Tolerance to furfural-induced stress is associated with pentose phosphate pathway genes ZWF1, GND1, RPE1, and TKL1 in Saccharomyces cerevisiae. Appl Microbiol Biotechnol 2006, 71:339-349.

23. Liu ZL, Moon J, Andersh BJ, Slininger PJ, Weber S: Multiple gene-mediated $\mathrm{NAD}(\mathrm{P}) \mathrm{H}$-dependent aldehyde reduction is a mechnism of in situ detoxification of furfural and 5-hydromethylfurfural by Saccharomyces cerevisiae. Appl Microbiol Biotechnol 2008, 81:743-753.

24. Hasunuma T, Sanda T, Yamada R, Yoshimura K, Ishii J, Kondo A: Metabolic pathway engineering based on metabolomic confers acetic and formic acid tolerance to a recombinant xylose-fermentating strain of Saccharomyces cerevisiae. Microb Cell Fact 2011, 10:2.

25. Singh KD, Schmalisch MH, StÜlke J, GÖrke B: Carbon catabolite repression in Bacillus subtilis:quantitative analysis of repression exerted by different carbon sources. J Bacteriol 2008, 190(21):7275-7284.

26. Oh DK, Kim SY, Kim JH: Increase of xylitol production rate by controlling redox potential in Candida parapsilosis. Biotechnol Bioeng 1998, 58:440-444.

27. Kang HY, Kim YS, Kim GJ, Seo JH, Ryu YW: Screening and characterization of flocculent yeast, Candida sp. HY200, for the production of xylitol from D-xylose. J Microbiol Biotechnol 2005, 15:362-367.

28. Kwon SG, Park SW, Oh DK: Increase of xylitol productivity by cell-recycle fermentation of Candida tropicalis using submerged membrane bioreactor. J Biosci Bioeng 2006, 101:13-18.

29. Guo C, Zhao C, He P, Lu D, Shen A, Jiang N: Screening and characterization of yeasts for xylitol production. J Appl Microbiol 2006, 101:1096-1104.

30. Sanchez B, Bautista J: Effects of furfural and 5-hydroxymethylfurfural on the fermentation of Saccharomyces cerevisiae and biomass production from Candida guilliermondii. Enzyme Microb Technol 1988, 5:315-318.

31. Preziosi-Belloy L, Nolleau V, Navarro JM: Fermentation of hemicellulosic sugars and sugar mixtures to xylitol by Candida parapsilosis. Enzyme Microb Technol 1997, 21(2):124-129.

32. Pscheidt B, Glieder A: Yeast cell factories for fine chemical and API production. Microb Cell Fact 2008, 7:25.

\section{Submit your next manuscript to BioMed Central and take full advantage of:}

- Convenient online submission

- Thorough peer review

- No space constraints or color figure charges

- Immediate publication on acceptance

- Inclusion in PubMed, CAS, Scopus and Google Scholar

- Research which is freely available for redistribution

Submit your manuscript at www.biomedcentral.com/submit 